La posición cíclica de la política fiscal en Colombia durante el periodo 1990-2015

\author{
Luis Hernando Portillo Riascos
}


La posición cíclica de la política fiscal en Colombia durante el periodo 1990-2015 Resumen: Este artículo busca determinar la posición cíclica de la politica fiscal en Colombia durante elperiodo 1990-2015. Para este propósito, se utilizan tres variables: el gasto del gobierno, el déficit fiscal ajustado cíclicamente y la deuda pública. Como resultado de este ejercicio, se concluye que la política fiscal en Colombia mostró una posición procíclica y asimétrica, lo que quiere decir que esta berramienta de política económica actuó como un mecanismo desestabilizador de la demanda agregada y contribuyó así a amplificar los efectos generados por los ciclos externos. Por componentes del gasto, la variable con un sesgo mucho más marcado por el ciclo económico fue la inversión pública.

Palabras clave: gasto público, politica fiscal, posición cíclica, vulnerabilidad macroeconómica. Clasificación JEL: E62, H61, H69, O23.

\section{The Cyclical Position of The Fiscal Policy in Colombia During the Period 1990-2015}

Abstract: This article seeles to determine the cyclical position of fiscal policy in Colombia during the period 1990-2015. For this purpose, three variables are used: government spending, cyclically adjusted fiscal deficit, and public debt. As a result of this exercise, it is concluded that fiscal policy in Colombia showed a procyclical and asymmetric position, which means that this economic policy tool acted as a destabilizing mechanism for aggregate demand and thus contributed to amplifying the effects generated by the external cycles. By components of expenditure, the variable with a much more marked bias due to the economic cycle was public investment.

Keywords: fiscal policy, macroeconomic vulnerability, public spending, cyclical position. 
La position cyclique de la politique budgétaire en Colombie au cours de la période 1990-201

Résumé: Cet article cherche à déterminer la position cyclique de la politique budgétaire en Colombie au cours de la période 1990-2015. À cette fin, trois variables sont utilisées: les dépenses publiques, le déficit budgétaire corrigé par des variations cycliques et la dette publique. À la suite de cet exercice, nous concluons que la politique budgétaire en Colombie a montré une position procyclique et asymétrique, ce qui signifie que la politique économique a agi comme un mécanisme de déstabilisation de la demande agrégée, lequel a contribué à amplifier les effets entrainés par les cycles externes. Dans l'approche macroéconomique par composantes de la dépense, l'investissement public était la variable avec le biais le plus marqué dû au cycle économique.

Mots clés: Dépenses publiques, politique budgétaire, position cyclique, vulnérabilité macroéconomique.

Cómo citar / How to cite this item:

Portillo Riascos, L. H. (2021). La posición cíclica de la política fiscal en Colombia durante el periodo 1990-2015. Lecturas de Economía, (95), 45-83.

https://doi.org/10.17533/udea.le.n95a343360 


\title{
La posición cíclica de la política fiscal en Colombia durante el periodo 1990-2015
}

\author{
Luis Hernando Portillo Riascos $\oplus^{a}$
}

-Introducción. -I. Revisión de la literatura. -II. Breve revisión del desempeño fiscal de Colombia. -III. Aspectos metodológicos. -VI. Resultados. -V. Discusión. -Conclusiones. -Referencias

Primera versión recibida el 06 de agosto de 2020; versión final aceptada el 16 de marzo de 2021

\section{Introducción}

El objetivo del presente artículo es determinar la posición de la política fiscal en Colombia frente al ciclo económico entre 1990 y 2015. El periodo analizado dentro de la investigación es de gran relevancia debido a la intensidad que ejercieron los ciclos comerciales y financieros sobre el ciclo económico colombiano, en un contexto de profundización de la apertura económica que se dio desde inicios de los noventa.

Por las características que asumen los ciclos externos en países como Colombia, lo que se argumenta es que estos generan una serie de distorsiones sobre la dinámica de sus principales agregados macroeconómicos. Lo que se esperaría en las economías en desarrollo — que están sujetas a los efectos de la restricción externa (Thirlwall, 1979; Ocampo, 2011, 2012) - es que la política económica contribuya a mitigar los choques de oferta (Agénor \& Montiel, 2000; Ocampo, 2011; 2012), siguiendo un patrón de manejo anticíclico. No obstante, desde el neoestructuralismo y, particularmente, desde la macroeconomía del desarrollo se plantea que, debido a las divergencias existentes entre los países en el contexto internacional - especialmente en los aspectos financieros y macroeconómicos (Ocampo, 2011)_, los países en desarrollo como Colombia tienden a aplicar unas

a Luis Hernando Portillo Riascos: docente de tiempo completo, departamento de Economía, Universidad de Nariño, Colombia. Dirección electrónica: luiher02@ucm.es https://orcid.org/0000-0003-3362-6934 
Portillo Riascos: La posición cíclica de la política fiscal en Colombia durante el periodo...

medidas de política económica que terminan amplificando los efectos de los ciclos externos, convirtiéndose así en un factor adicional de exposición que tiene repercusiones en términos de vulnerabilidad macroeconómica - VM(Comisión Económica para América Latina y el Caribe [CEPAL], 2001; Ffrench-Davis \& Ocampo, 2001; Kaminsky et al., 2004; Pérez, 2015).

La VM se define como el grado de exposición de la economía de un país ante la probabilidad de ocurrencia de un shock externo y la capacidad para afrontar los efectos adversos que este genere (Atkins et al., 1998; Cordina, 2004; Briguglio et al., 2009; Guillaumont, 2013, 2017). Desde esta perspectiva, la VM tiene un carácter exógeno, dada la influencia que ejercen los shocks externos en la dinámica macroeconómica de los países en desarrollo. No obstante, debido al tipo de manejo de las autoridades en la gestión de la política económica, lo que se plantea es que la VM también tiene un origen interno (Portillo, 2020a, 2020b). En esta línea, la VM se genera por la interacción entre los shocks externos, tanto comerciales como financieros, y las medidas de política económica que adoptan los gobiernos (Portillo, 2020a).

La influencia de la política económica dentro de la VM de un país se ve reflejada en las decisiones que toman los gobiernos en materia fiscal, monetaria y cambiaria. De acuerdo con este planteamiento, las medidas de política económica aplicadas en este tipo de países, en vez de mitigar los efectos desestabilizadores de los shocks externos, terminan potenciándolos (CEPAL, 2001; French-Davis \& Ocampo, 2001; Kaminsky et al., 2004; Ocampo, 2011, 2012; Pérez, 2015; Portillo, 2020a, 2020b). Desde este presupuesto, la gestión gubernamental asume una posición procíclica, bien sea porque las decisiones de las autoridades sean deliberadas en este sentido, o bien, porque tienen unos objetivos diferentes.

Desde el punto de vista metodológico, se evalúa si los gobiernos son capaces de corregir los sesgos procíclicos inducidos por los shocks externos, o si - por el contrario — terminan amplificándolos. Si sucede lo primero, los gobiernos contribuyen a estabilizar el ciclo económico; de lo contrario, las medidas de política económica se convierten en un germen de inestabilidad y volatilidad macroeconómica. 
Para cumplir con los objetivos trazados, este artículo se encuentra estructurado en cuatro secciones, además de esta introducción. En la primera sección se hace un breve repaso de la literatura relacionada con la importancia y los efectos del manejo de la política fiscal sobre los principales agregados macroeconómicos, lo cual permite establecer el vínculo entre la gestión fiscal y la vulnerabilidad e inestabilidad macroeconómica. En la segunda sección se hace una breve revisión del comportamiento de algunos indicadores fiscales para la economía colombiana en el periodo en mención. En la tercera, se exponen las referencias metodológicas y en la cuarta se detallan los resultados obtenidos a partir del análisis empírico, incluyendo una discusión con los resultados obtenidos en otras investigaciones, tanto para el caso colombiano como para el latinoamericano. Finalmente, se esbozan las conclusiones más relevantes del estudio.

\section{Revisión de la literatura}

Durante las últimas décadas se han publicado una serie de estudios que evalúan el manejo de la política fiscal frente al ciclo económico en diferentes países (Gavin \& Perotti, 1997; Kaminsky et al., 2004; Klemm, 2014). Gran parte de estas investigaciones se han direccionado hacia el análisis de las economías en desarrollo, en las que se concluye que este instrumento de gestión macroeconómica ha adoptado un sesgo mayormente procíclico (Clements et al., 2007; Ilzetzki \& Végh, 2008; Lozano et al., 2013; CEPAL, 2014; Klemm, 2014). Dichos estudios también han cubierto el caso colombiano, aunque en el marco del análisis del conjunto de países latinoamericanos (Toro \& Lozano, 2007; Lozano, 2009; Ocampo, 2011).

Desde la perspectiva de este artículo, no solamente importa determinar la posición cíclica de la política fiscal, tal y como se deriva de los estudios referenciados. Antes bien, lo que se busca es examinar los efectos que genera dicho manejo en el conjunto de la economía, especialmente por las consecuencias que se pueden desencadenar en las variables reales. Lo que se plantea en el marco del neoestructuralismo es que, dependiendo del tipo de gestión de la política fiscal, esta herramienta puede convertirse en un instrumento fundamental para la consecución de los equilibrios 
Portillo Riascos: La posición cíclica de la política fiscal en Colombia durante el periodo...

macroeconómicos de corto y mediano plazo. Empero, si la política fiscal adopta un sesgo procíclico — como habría sucedido en la mayoría de los países latinoamericanos en las últimas décadas, incluido Colombia, dicho instrumento pasaría a convertirse en una fuente de inestabilidad macroeconómica, con lo cual los gobiernos terminan potenciando los efectos negativos generados tanto por los ciclos comerciales como por los financieros.

Antes de describir los mecanismos a través de los cuales el manejo de la política fiscal contribuye a exacerbar la inestabilidad real de las economías en desarrollo, es necesario advertir que los shocks externos (comerciales y financieros) alteran el espacio de la política económica y su rol como mecanismo de estabilización (Ffrench-Davis, 2008). La razón está en que tales shocks son excepcionales y, en esta medida, obligan a respuestas de política económica de tipo discrecional - $\mathrm{y}$, en muchos casos, abrupta-, mas no por mecanismos automáticos. En este marco, mientras que los desequilibrios macroeconómicos demandan la intervención fiscal, el comportamiento de la actividad económica limita su ejercicio (Jiménez \& Fanelli, 2009).

La reducción del espacio fiscal también se presenta por el conflicto en los objetivos y recursos que persiguen los distintos instrumentos de política económica (Ffrench, 2008), lo cual plantea graves contradicciones a la hora de intervenir en las variables económicas. Como resultado de la dinámica enunciada, el espacio fiscal de las economías en desarrollo termina alineándose con los movimientos de los flujos internacionales de capital y de los términos de intercambio, adoptando de esta manera un sesgo procíclico (Ocampo, 2007; Jiménez \& Fanelli, 2009). Además, el gasto público se vuelve intermitente (stop and go), abandonando su rol contracíclico y estabilizador, lo que, en consecuencia, hace que pierda eficiencia en términos de su contribución al crecimiento económico.

Las mayores dificultades se presentan en las fases recesivas del ciclo económico, en las cuales la política fiscal es incapaz de afrontar la caída en la demanda agregada, haciendo que esta función recaiga en otros instrumentos de intervención, como la política monetaria y cambiaria, que individualmente no son las más adecuadas para recuperar el dinamismo de la economía (French-Davis, 2008). Al final, la política fiscal terminaría siendo muy 
expansiva en las fases de auge y demasiado restrictiva e ineficiente durante los periodos recesivos (Ffrench-Davis, 2005; Gavin \& Perotti, 1997; Kaminsky et al., 2004; Ffrench-Davis, 2005; Ocampo, 2007, 2012).

Sobre las razones que explican los rasgos procíclicos en el manejo de la política fiscal, especialmente en los países en desarrollo, hay varias referencias dentro de la literatura. En primer lugar, como se ha mencionado, dicha manera de actuar por parte de las autoridades tiene que ver con la existencia de una serie de asimetrías en el sistema económico y financiero internacional, las cuales terminan limitando el espacio de actuación (policy space) de los gobiernos de este tipo de países (CEPAL, 2001; Ffrench-Davis \& Ocampo, 2001; Ocampo, 2011). Un segundo fenómeno que ayuda a explicar el sesgo procíclico de la política fiscal es el llamado efecto voracidad, en el que los grupos de interés presionan a los gobiernos para que incrementen el gasto público durante las fases de auge de la economía, con lo cual no se genera un ahorro fiscal suficiente que se pueda utilizar durante los periodos de desaceleración de la economía (Gavin \& Perotti, 1997).

Un tercer factor que explica la postura de los gobiernos frente al ciclo económico tiene que ver con las asimetrías en el acceso al endeudamiento a las cuales se enfrentan las economías en desarrollo. Así, mientras en el auge los gobiernos tienen una gran disponibilidad de financiamiento, en los periodos de desaceleración de la economía terminan enfrentándose a los efectos de la restricción del crédito, reduciendo así su capacidad de intervención en la economía (Gavin \& Perotti, 1997; Kaminsky et al., 2004).

Una razón adicional que explicaría el sesgo procíclico de la política fiscal está asociada con la posición que asumen los agentes externos, representados tanto en los prestamistas como en las entidades multilaterales (Fondo Monetario Internacional, Banco Mundial, etcétera). Así, mientras en las fases de bonanza de la economía dichos agentes contribuyen para que haya una mayor disponibilidad de recursos para este tipo de países, durante los periodos de ralentización del crecimiento económico, e incluso en las crisis, entran a presionar a los gobiernos para que realicen una serie de ajustes que garanticen la sostenibilidad fiscal. Lo anterior implica corregir precipitadamente los desequilibrios ocasionados al finalizar los periodos de auge de la economía 
Portillo Riascos: La posición cíclica de la política fiscal en Colombia durante el periodo...

(Kaminsky et al., 2004). Al final, lo que les interesa a dichos agentes es que se garantice el pago de la deuda. Dicho mecanismo, nuevamente, resta recursos para que los gobiernos utilicen el gasto público con un propósito contracíclico.

Además de las razones esbozadas anteriormente, habría otra serie de fenómenos que también permiten explicar la posición procíclica en el manejo de la política fiscal, tales como los problemas institucionales, la corrupción, las normas fiscales, entre otros (Toro \& Lozano, 2007).

Desde la perspectiva abordada en este artículo, el problema que se deriva del hecho de que las autoridades no utilicen la política fiscal con un propósito contracíclico es que, al final, terminan exacerbando los efectos negativos generados como resultado de los shocks externos, y en esta medida dicha herramienta se convierte en una fuente de inestabilidad macroeconómica, por cuanto hace que la economía se vuelva más vulnerable ante la eventualidad de algún tipo de evento exógeno.

Lo que se ha advertido desde el enfoque keynesiano es que, así como la política fiscal puede ayudar a suavizar el ciclo económico (asumiendo una posición contracíclica), e incluso acelerar el crecimiento de la economía, este instrumento de política económica igualmente se puede convertir en una fuente de volatilidad macroeconómica, por los efectos que el manejo de esta herramienta genera sobre el PIB tanto por la vía del consumo como de la inversión. En este sentido, son varios los estudios que advierten acerca de lo perniciosa que resulta la volatilidad del PIB en términos del crecimiento económico (Ramey \& Ramey, 1995; Loayza \& Raddatz, 2007; Larraín \& Parro, 2008; Ffrench-Davis, 2010; Pineda \& Cárcamo, 2013; Pérez, 2015; Titelman \& Pérez, 2015). Por lo tanto, la política fiscal también estaría contribuyendo a ahondar este fenómeno.

Frente a la posición que debe adoptar la política fiscal respecto al ciclo económico, hay varios planteamientos dependiendo del enfoque, ya sea neoclásico o keynesiano (Gavin \& Perotti, 1997; Martner, 2007; Ilzetzki \& Végh, 2008; Lozano, 2009). Mientras en el primer caso la política fiscal debería ser acíclica — dejando el peso del ajuste sobre los estabilizadores automáticos, sin requerir una acción discrecional de los gobiernos-, desde una óptica 
keynesiana la política fiscal debería adoptar una posición contracíclica, lo que quiere decir que en las fases de auge (crisis), además del papel que pueden jugar los estabilizadores automáticos, hay que incrementar (reducir) el recaudo y reducir (aumentar) el gasto, lo cual permitiría actuar a los gobiernos tanto en las fases recesivas como contractivas y contribuir de esta manera a la estabilización del producto.

\section{Breve revisión del desempeño fiscal de Colombia}

Una vez abordados los principales referentes teóricos, en esta sección de describen algunos resultados fiscales alcanzados por Colombia a lo largo del periodo analizado. Es importante advertir que la finalidad de este ejercicio no es realizar un análisis exhaustivo de las características de la política fiscal colombiana; más bien se trata de hacer un balance muy general de la dinámica fiscal dentro del periodo investigando, identificando algunos cambios relevantes. Siguiendo la estructura presupuestal, en la primera parte se analiza la dinámica de los ingresos, posteriormente se hace una revisión de los gastos y por último se estudia el balance fiscal.

\section{A. Ingresos fiscales}

En la Figura 1 se muestran los ingresos recaudados por el Gobierno Nacional Central (GNC) en el periodo 1990-2015. Como se puede observar, la mayor parte de los ingresos son de naturaleza tributaria, que representaron en promedio el $88,1 \%$ del total para el lapso estudiado. Dentro de los ingresos tributarios, los rubros más representativos corresponden al impuesto de renta, el impuesto al valor agregado (interno y externo), el gravamen a los movimientos financieros (desde 1999), el impuesto a la riqueza (desde 2002) y la contribución sobre la renta para la equidad (CREE) creado mediante Ley 1607 de 2012 (desde 2013).

Sin entrar a discutir acerca de la progresividad de la estructura tributaria, lo más destacable desde la perspectiva de esta investigación es el crecimiento de la participación de los ingresos tributarios en el PIB (Tabla 1), particularmente desde inicios de la década del año 2000. En términos reales, se pasó de una 
Portillo Riascos: La posición cíclica de la política fiscal en Colombia durante el periodo...

contribución media del 8,2\% (en porcentaje del PIB) entre 1990 y 1999 a un promedio del $12,7 \%$ entre 2000 y 2015. Dicha participación se ha ido incrementando hasta llegar a una media del 14,3\% entre 2012 y 2015. Para entender esta dinámica, hay que tener en cuenta varios factores, entre ellos, el desempeño del PIB, que ha permitido, sobre todo en los últimos años, ampliar la base tributaria. Además, es importante destacar las reformas tributarias que se han realizado a lo largo del periodo, especialmente hacia finales de los noventa, cuando se buscó incrementar el recaudo de ingresos no solamente para el GNC, sino también para las entidades territoriales (Lozano, 2009).

Figura 1. Composición de los ingresos del GNC, periodo 1990-2015

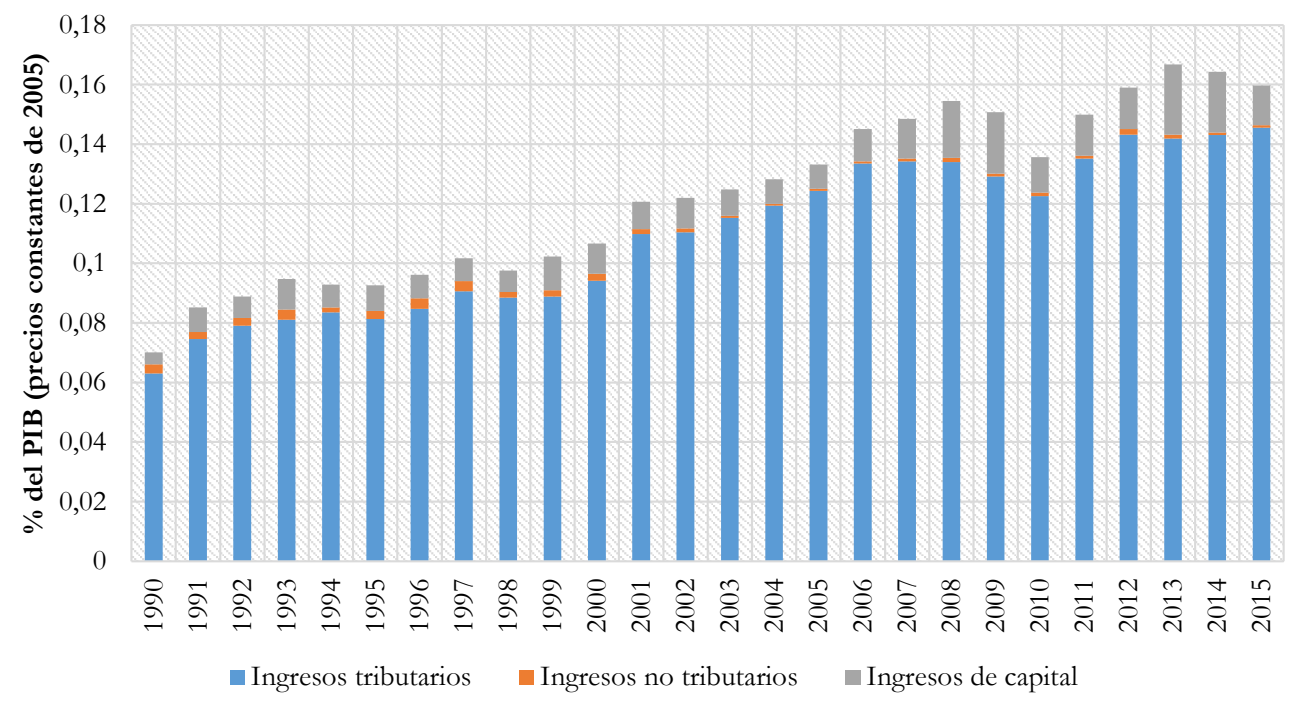

Fuente: elaboración propia con información del Banco de la República y el Ministerio de Hacienda.

La influencia de los ciclos externos sobre los ingresos tributarios fue muy evidente durante el periodo investigado, especialmente en la fase marcada por el boom de las commodities, cuyo efecto se pudo observar tanto en los impuestos directos como en los ingresos de capital; en este último caso, a través de la participación que tiene el Estado en las utilidades de las empresas públicas (sobre todo en Ecopetrol). El fenómeno descrito se puede observar en la Figura 2, en la que se presenta la dinámica de la renta de los recursos naturales 
( \% del PIB), sobre la cual el Estado tiene una importante participación ${ }^{1}$. Para el caso colombiano, estos recursos representaron una media del $4,9 \%$ del PIB entre 1990 y 2015, que se incrementó hasta el 6,8\% en el periodo del boom de las commodities (2004-2013), alcanzando el máximo porcentaje en el 2011 $(9,3 \%)^{2}$.

Tabla 1. Tasa de crecimiento medio (real) y volatilidad de los ingresos del GNC. Periodo 1990-2015

\begin{tabular}{llcccc}
\hline \multirow{2}{*}{ Indicador } & \multirow{2}{*}{ Concepto de ingreso } & \multicolumn{4}{c}{ Periodo } \\
\cline { 3 - 6 } & & $\mathbf{1 9 9 0 - 1 9 9 9}$ & $\mathbf{2 0 0 0 - 2 0 1 5}$ & $\mathbf{2 0 0 5 - 2 0 1 5}$ & $\mathbf{1 9 9 0 - 2 0 1 5}$ \\
\hline \multirow{2}{*}{$\begin{array}{l}\text { Tasa de } \\
\text { crecimiento }\end{array}$} & Ingresos totales & $\mathbf{6 , 8} \%$ & $7,0 \%$ & $6,7 \%$ & $6,9 \%$ \\
medio & Ingresos tributarios & $5,8 \%$ & $7,4 \%$ & $6,5 \%$ & $6,8 \%$ \\
\hline Desviación & Ingresos de capital & $15,3 \%$ & $5,2 \%$ & $9,4 \%$ & $8,7 \%$ \\
estándar de la tasa & Ingresos totales & $7,3 \%$ & $6,1 \%$ & $7,0 \%$ & $6,6 \%$ \\
crecimiento & Ingresos tributarios & $7,2 \%$ & $5,7 \%$ & $5,8 \%$ & $6,4 \%$ \\
medio & Ingresos de capital & $40,8 \%$ & $29,2 \%$ & $33,2 \%$ & $143,7 \%$ \\
\hline Coeficiente de & Ingresos totales & 1,04 & 0,84 & 1,00 & 0,92 \\
variación de la & Ingresos tributarios & 1,20 & 0,75 & 0,87 & 0,91 \\
tasa crecimiento & Ingresos de capital & 1,92 & 3,23 & 2,29 & 2,56 \\
medio & & & & & \\
\hline
\end{tabular}

Fuente: elaboración propia con información del Banco de la República y el Ministerio de Hacienda.

1 La renta de los recursos naturales se define como la diferencia entre el precio del bien en el mercado internacional y los costos de producción (Campodónico, 2004). La participación del Estado en dicha renta se da a través de múltiples vías, que pueden ser directas, como sucede en el caso del impuesto de renta, indirectas, cuando hay impuestos al consumo o las regalías, y en otros casos, como el de Colombia, por medio de la participación del Estado en las empresas públicas, siendo la más importante Ecopetrol (Portillo, 2015).

2 De acuerdo con las estadísticas del Ministerio de Hacienda, los ingresos petroleros representaron una media del 2,24\% del PIB dentro del presupuesto del GNC en el subperiodo 2011-2015, lo que equivale al 13,8\% del mismo. 
Portillo Riascos: La posición cíclica de la política fiscal en Colombia durante el periodo...

Figura 2. Rentas totales de los recursos naturales de Colombia (\% del PIB)

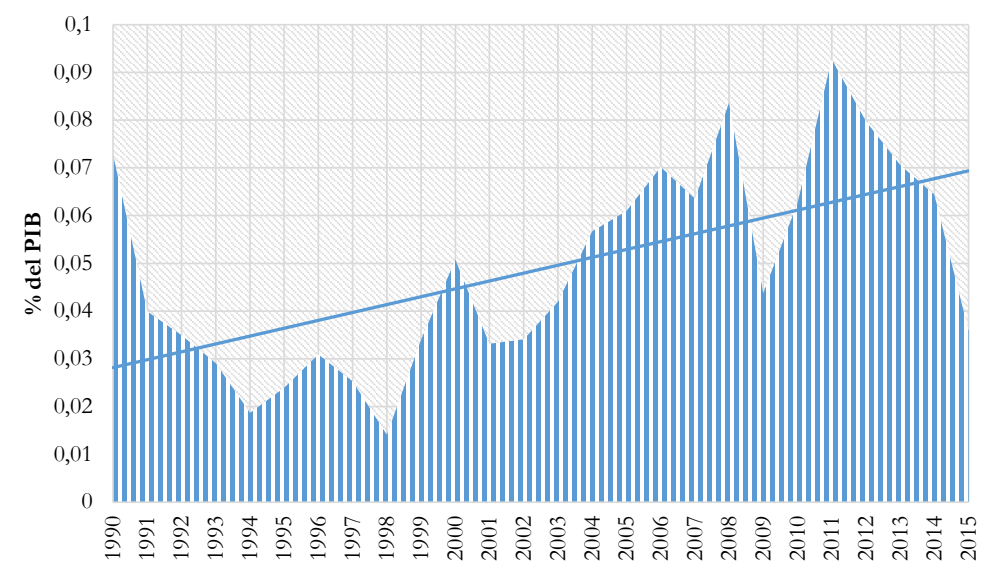

Fuente: Banco Mundial.

Los ingresos de capital ${ }^{3}$ también resultaron significativos durante el periodo 1990-2015 (véase Figura 1). De hecho, en promedio, representaron el 1,1\% del PIB, es decir, un $8,9 \%$ de los ingresos totales. Entre los años 2004 y 2015, dichos porcentajes fueron del 1,5\% y el 9,6\%, respectivamente. Además, se destaca que el crecimiento de los ingresos de capital $(8,7 \%)$, que, en términos anuales, estuvo por encima del incremento reportado por los ingresos totales $(6,9 \%)$ y los tributarios $(6,8 \%)$. Ahora bien, por las características de estos ingresos, esta fuente de recursos terminó siendo la más volátil dentro de la estructura de ingresos del GNC (véase Tabla 1).

La mayor parte de los ingresos de capital correspondieron a los excedentes financieros de Ecopetrol, cuya contribución entre los años 2000 y 2015 fue del $72 \%$ del total (además del aporte que hace en términos de la renta de sociedades). Dentro de los ingresos de capital también se cuenta con los recursos provenientes de las privatizaciones, que reportaron un flujo de ingresos significativo tanto en los noventa como en los 2000.

3 Dentro de los ingresos de capital se agruparon, principalmente, los fondos especiales, los rendimientos financieros totales y los excedentes financieros de las empresas en las que tiene participación el Estado (GNC). 


\section{B. Gasto público}

El análisis del gasto público es muy relevante dentro de este artículo porque esta variable es la referencia más importante para determinar la posición cíclica de la política fiscal. Además, hay que tener en cuenta que, para las economías en desarrollo, el gasto público es el principal instrumento de redistribución, ya que esta no opera por la vía de los ingresos (CEPAL, 2014). Dicho fenómeno se explica porque la presión fiscal en este tipo de países continúa siendo muy baja — comparada con los países desarrollados—, tal y como se pudo observar en el apartado anterior para el caso colombiano.

En la Figura 3 se muestran las principales características del gasto público en términos de su composición. Como se puede observar, de acuerdo con el crecimiento y la participación en el PIB, los gastos han tenido una dinámica similar a la de los ingresos, aunque el incremento de los primeros evidencia mayores diferencias entre subperiodos. Dicho fenómeno resulta mucho más claro durante los noventa, cuando el crecimiento acelerado del gasto público se explica, fundamentalmente, por las competencias asumidas por el Estado a partir de la Constitución de 1991.

Como resultado de los desajustes fiscales que se generaron durante los noventa, en medio de una crisis económica, financiera y fiscal muy fuerte, se emprendieron una serie de acciones para racionalizar el gasto público (entre otras, la Ley 550 de 1999, la Ley 617 de 2000, la Ley 715 de 2001 y la Ley 819 de 2003). Los efectos de tales medidas se pueden observar en la dinámica del gasto corriente, el cual, desde 2001, no ha incrementado su participación en el gasto total (\% del PIB) (Figura 3). Esta situación también se refleja en la dinámica de los gastos de funcionamiento.

Otro factor que contribuyó a limitar el crecimiento del gasto fue la reducción de los intereses de la deuda pública, los cuales habían mostrado un comportamiento ascendente durante la segunda mitad de los noventa. Con relación a los gastos de inversión, estos han seguido la dinámica del ciclo económico. Como se verá más adelante, dicho fenómeno se explica porque este es el rubro más flexible dentro de la estructura de presupuesto. 
Portillo Riascos: La posición cíclica de la política fiscal en Colombia durante el periodo...

Figura 3. Composición funcional del gasto del GNC, periodo 1990-2015

\section{Panel A}

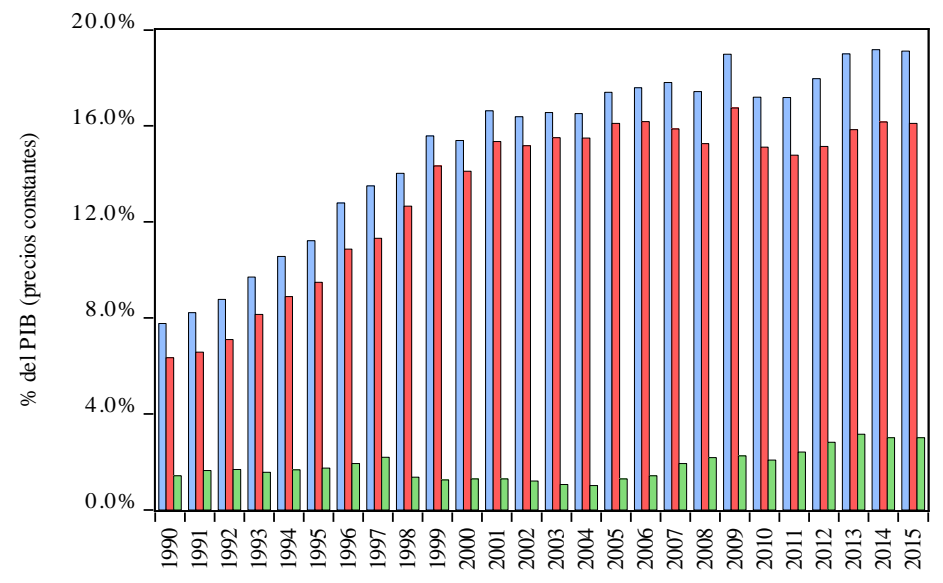

Gasto total (incluye intereses de la deuda interna y externa)

Gasto corriente

Inversión

Panel B

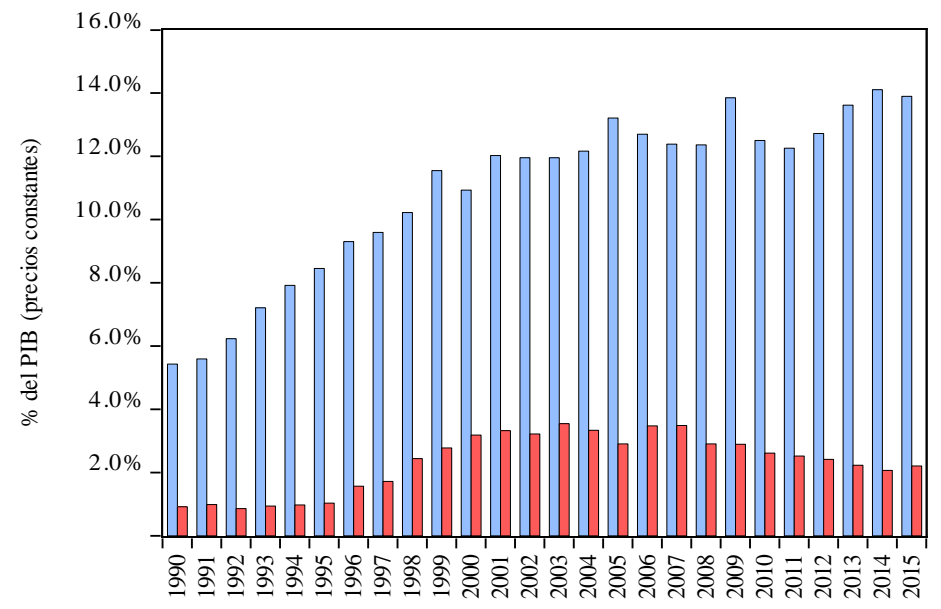

Funcionamiento

Intereses de la deuda (interna y externa)

Fuente: elaboración propia con información del Banco de la República y el Ministerio de Hacienda. 
El cambio en la dinámica del gasto a partir de 2000 se muestra en la Tabla 2. En general, se destaca una reducción en su tasa de crecimiento (en términos reales), pasando de un promedio anual del 8,9\% entre 1990 y 1999 a una tasa del 4,9\% entre el 2000 y el 2015. Desde luego, el efecto de las medidas de racionalización del gasto es evidente. Además, dicha dinámica se dio en el componente más importante: los gastos corrientes, y dentro de estos, en los gastos de funcionamiento, cuya tasa de crecimiento prácticamente se redujo a la mitad. Asimismo, se puede ver una política clara de desendeudamiento, logrando una disminución sustantiva en la tasa de expansión de los intereses de la deuda pública.

Tabla 2. Tasa de crecimiento y volatilidad de los gastos del GNC (precios constantes de 2005). Periodo 1990-2015

\begin{tabular}{|c|c|c|c|c|c|}
\hline \multirow{2}{*}{ Indicador } & \multirow{2}{*}{ Concepto de ingreso } & \multicolumn{4}{|c|}{ Periodo } \\
\hline & & 1990-1999 & $2000-2015$ & $2005-2015$ & $1990-2015$ \\
\hline \multirow{5}{*}{$\begin{array}{l}\text { Tasa de } \\
\text { crecimiento } \\
\text { medio anual } \\
\text { (acumulada) }\end{array}$} & Gasto total GNC & $8,9 \%$ & $4,9 \%$ & $4,9 \%$ & $6,4 \%$ \\
\hline & Gastos corrientes & $9,5 \%$ & $5,5 \%$ & $6,0 \%$ & $7,0 \%$ \\
\hline & $\begin{array}{l}\text { Intereses de la deuda } \\
\text { (interna y externa) }\end{array}$ & $14,4 \%$ & $2,7 \%$ & $0,7 \%$ & $7,0 \%$ \\
\hline & Gastos de funcionamiento & $10,5 \%$ & $5,4 \%$ & $5,8 \%$ & $7,3 \%$ \\
\hline & Gastos de inversión & $1,3 \%$ & $10,1 \%$ & $15,4 \%$ & $6,6 \%$ \\
\hline \multirow{7}{*}{$\begin{array}{l}\text { Desviación } \\
\text { estándar de la tasa } \\
\text { crecimiento anual }\end{array}$} & Gasto total GNC & $10,1 \%$ & $4,4 \%$ & $4,8 \%$ & $7,5 \%$ \\
\hline & Gastos corrientes & $5,7 \%$ & $4,4 \%$ & $4,8 \%$ & $5,3 \%$ \\
\hline & $\begin{array}{l}\text { Intereses de la deuda } \\
\text { (interna y externa) }\end{array}$ & $18,4 \%$ & $10,2 \%$ & $10,6 \%$ & $140,3 \%$ \\
\hline & Gastos de funcionamiento & $5,2 \%$ & $5,5 \%$ & $5,7 \%$ & $6,2 \%$ \\
\hline & Gasto total GNC & 1,07 & 0,87 & 0,94 & 1,11 \\
\hline & Gastos de inversión & $16,9 \%$ & $14,3 \%$ & $14,0 \%$ & $15,8 \%$ \\
\hline & Gastos corrientes & 0,59 & 0,79 & 0,79 & 0,74 \\
\hline \multirow{3}{*}{$\begin{array}{l}\text { Coeficiente de } \\
\text { variación de la tasa } \\
\text { crecimiento anual }\end{array}$} & $\begin{array}{l}\text { Intereses de la deuda } \\
\text { (interna y externa) }\end{array}$ & 1,17 & 3,23 & 8,60 & 1,84 \\
\hline & Gastos de funcionamiento & 0,44 & 1,00 & 0,95 & 0,80 \\
\hline & Gastos de inversión & 5,86 & 1,31 & 0,86 & 1,96 \\
\hline
\end{tabular}

Fuente: elaboración propia con información del DANE, el Banco de la República y el Ministerio de Hacienda. 
Portillo Riascos: La posición cíclica de la política fiscal en Colombia durante el periodo...

Con el propósito de analizar los efectos que pudo generar el gasto público sobre el crecimiento económico, es interesante ver que, mientras en los noventa los gastos de inversión solamente crecieron a una media del $1,3 \%$ anual, en el lapso 2000-2015 dicho porcentaje fue del 10,1\%, llegando al $15,4 \%$ en el periodo del boom de las commodities (2005-2014). En estos dos últimos subperiodos (2000-2015 y 2005-2014), los gastos de inversión crecieron por encima de los rubros de gastos corrientes, que es lo contrario a lo que sucedió en los noventa.

Un elemento importante por destacar dentro del análisis es que, a pesar de los cambios que se dieron en la estructura del gasto entre los noventa y los 2000, la volatilidad no se ha reducido significativamente (Tabla 2). Esta situación es muy evidente tanto en el componente de gastos de funcionamiento como en los intereses de la deuda. Y a pesar de que se esperaría lo contrario, donde sí se ha presentado una disminución de la volatilidad es en los gastos de inversión, pues allí se supone que hay mayores ajustes en los tiempos de crisis.

\section{Deuda pública}

Dentro de la gestión fiscal de las economías en desarrollo, una de las principales preocupaciones está relacionada con la deuda pública, particularmente con la de origen externo. Dicha situación se explica por los problemas que esta variable puede generar sobre el resto de la economía, sobre todo porque en ciertos momentos se pueden presentar descalces tanto en moneda como en plazos, lo que ocasionaría graves problemas en el manejo macroeconómico (Eichengreen et al. 2007; Ocampo, 2012; CEPAL, 2014). En la Figura 4 se muestra el comportamiento la deuda del GNC por residencia. Hay dos elementos que son muy claros: a) los cambios en la composición y b) la estabilización y, durante varios años, caída de la ratio de la deuda pública sobre el PIB.

Con relación a la residencia de la deuda pública, es muy clara la tendencia a privilegiar la deuda interna, lo que ha permitido la reducción del peso de los pasivos externos dentro de la estructura general. Respecto a la deuda externa pública, lo que se puede ver es que mientras esta variable creció a un ritmo 
muy acelerado entre 1996 y 2002, en los años siguientes la tasa de crecimiento estuvo por debajo de la del PIB, lo que hace que la relación disminuya. El punto de inflexión se ubica nuevamente en 2013, cuando la ratio nuevamente se incrementó.

Figura 4. Deuda del GNC por residencia (\% del PIB), periodo 1990-2015

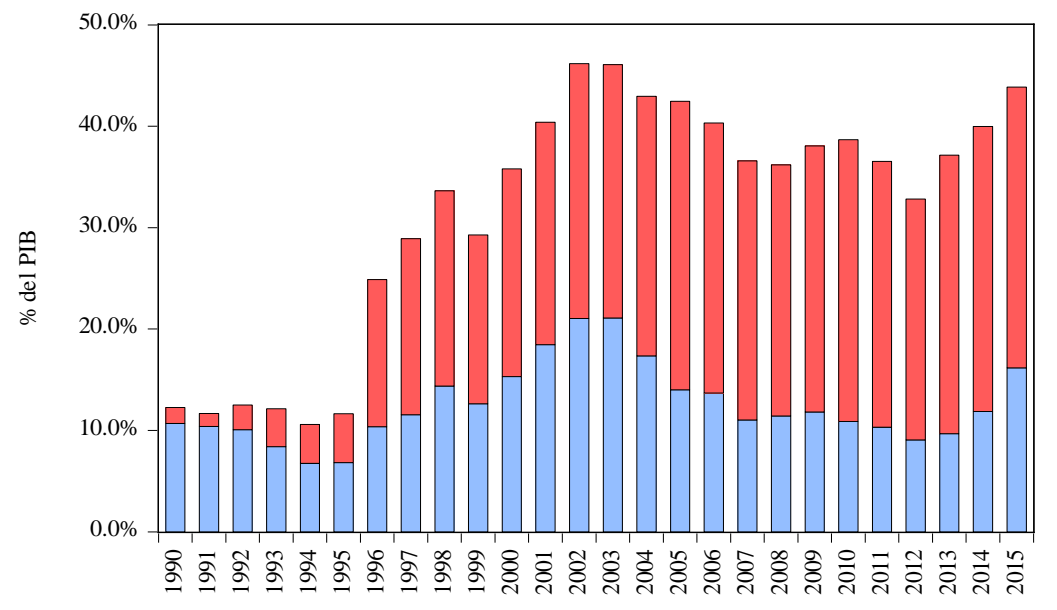

$\square$ Deuda externa $\square$ Deuda interna

Fuente: elaboración propia a partir de la información del Ministerio de Hacienda.

En línea con el contexto económico y fiscal al que se enfrentó la economía colombiana durante la primera década del siglo XXI, el comportamiento de la deuda pública se explicó por la conjunción de cuatro factores: la expansión del PIB, la profundización y dinamismo del mercado financiero local, la mayor facilidad en el acceso al financiamiento externo respecto a las décadas previas (Ocampo, 2007) y la apreciación del peso colombiano (especialmente desde el 2003).

\section{Balance fiscal}

Una vez se examinó por separado el comportamiento tanto de los ingresos como de los gastos, es momento de analizar el resultado conjunto de estas dos variables. Como se puede observar en la Figura 5, la característica 
Portillo Riascos: La posición cíclica de la política fiscal en Colombia durante el periodo...

fundamental del periodo analizado es un déficit presupuestario persistente, que fue creciente durante los noventa, pero luego se redujo hasta la llegada de la crisis financiera y económica de los países desarrollados entre el 2007 y el 2009. Posteriormente, se retomó la senda deficitaria hasta finalizar el 2015. Los años con mayor déficit presupuestario del GNC estuvieron entre 1996 y 2005, cuando, en promedio, este indicador se ubicó en el $4 \%$ del PIB para el balance real y $4,5 \%$ para el balance total (precios constantes).

Figura 5. Balance fiscal del GNC (\% del PIB), periodo 1990-2015

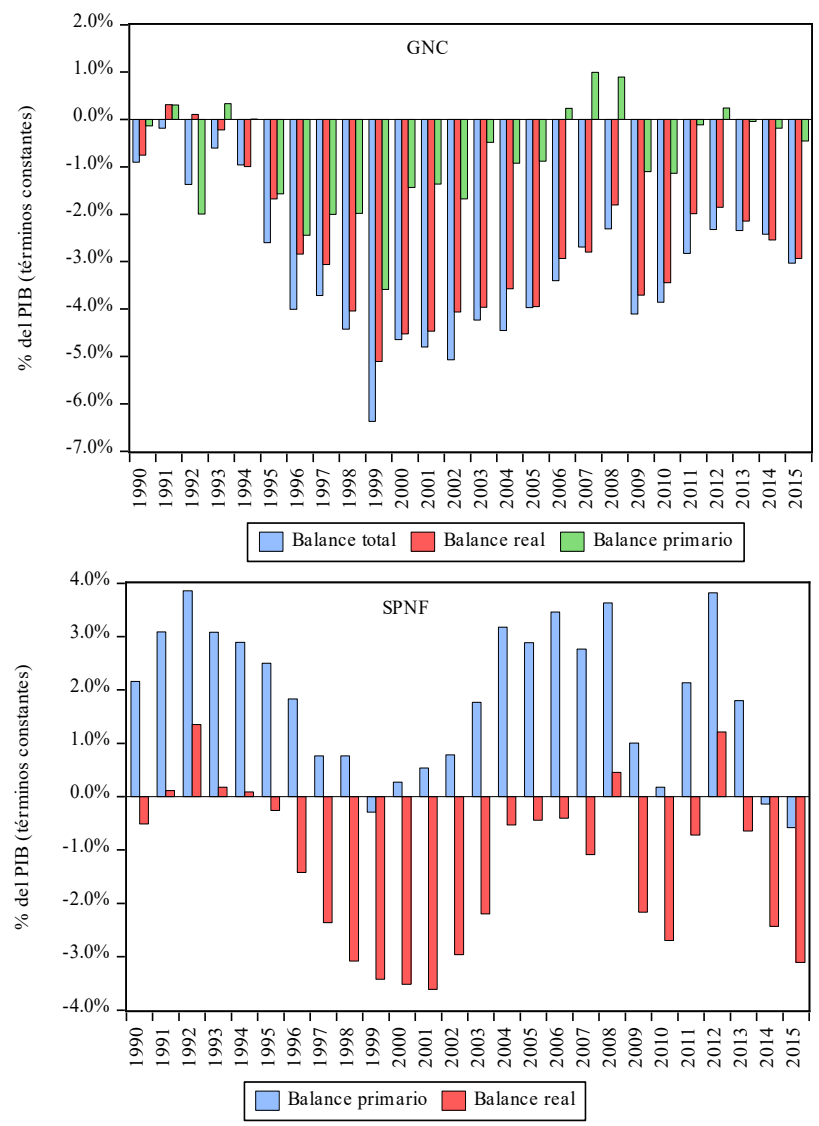

Fuente: elaboración propia con información del Ministerio de Hacienda. 
Para Rincón et al. (2004) y Lozano (2009), el balance fiscal del GNC de Colombia tiene un componente estructural muy acentuado que genera poca flexibilidad del gasto, que a su vez se explicaría por las disposiciones señaladas en la Constitución Política de 1991 (Echeverry et al., 2006; Rentería \& Echeverry, 2007; Lozano et al., 2008).

La reducción del déficit fiscal desde 1999, que marca un quiebre muy claro en el periodo de análisis, se explica por varios factores: el mayor crecimiento de la economía colombiana durante los 2000, la disminución de la tasa de expansión del gasto asociada a las medidas de racionalización aplicadas a finales de los noventa, el menor peso de la deuda pública dentro del PIB, la apreciación de la moneda, las bajas tasas de interés (locales e internacionales) y el incremento del recaudo fiscal (Toro \& Lozano, 2007; Lozano, 2009; Ocampo, 2011).

Por niveles de gobierno, fue el GNC el que más explicó el estado presupuestario del sector público, puesto que su balance (primario, real y total) fue deficitario en prácticamente todos los años (Figura 5). Con relación al sector público no financiero (SPNF), hay varios años con un balance primario positivo, lo que implica que son los intereses de la deuda los que al final terminan explicando el desajuste entre los ingresos y los gastos. De cualquier manera, hay una diferencia muy marcada entre el déficit fiscal del GNC y el del SPNF.

La diferencia entre la dinámica de los ingresos y la de los gastos entre las décadas de los noventa y los 2000 se puede observar en la Tabla 3. Así, mientras en los años de 1990 los ingresos se expandieron por debajo de la tasa de crecimiento del gasto, en los años del 2000 sucedió lo contrario. Dicho comportamiento explica la reducción del déficit fiscal durante este periodo. No obstante, como se verá más adelante, cuando el incremento del gasto se compara con la tasa de expansión del PIB, se encuentra que el primero, en la mayoría de los casos, fue superior, generando un resultado procíclico dentro de la actividad económica. 
Portillo Riascos: La posición cíclica de la política fiscal en Colombia durante el periodo...

Tabla 3. Diferencia entre la tasa de crecimiento anual (real) de los ingresos y los gastos del GNC. Periodo 1990-2015

\begin{tabular}{llcccc}
\hline \multirow{2}{*}{ Variable } & Indicador & \multicolumn{4}{c}{ Periodo } \\
\cline { 3 - 5 } Ingresos & Ingresos totales (ITot) & $6,8 \%$ & $7,0 \%$ & $6,7 \%$ & $6,9 \%$ \\
& Ingresos tributarios (Itr) & $5,8 \%$ & $7,4 \%$ & $6,5 \%$ & $6,8 \%$ \\
& Ingresos de capital (Ik) & $15,3 \%$ & $5,2 \%$ & $9,4 \%$ & $8,7 \%$ \\
& Gasto total (Gtot) & $8,9 \%$ & $4,9 \%$ & $4,9 \%$ & $6,4 \%$ \\
\multirow{3}{*}{ Gastos } & Gastos corrientes (Gc) & $9,5 \%$ & $5,5 \%$ & $6,0 \%$ & $7,0 \%$ \\
& Intereses de la deuda (interna y & $14,4 \%$ & $2,7 \%$ & $0,7 \%$ & $7,0 \%$ \\
& externa)(Gint) & & & & $1990-2015$ \\
& Gastos de funcionamiento (Gf) & $10,5 \%$ & $5,4 \%$ & $5,8 \%$ & $7,3 \%$ \\
& Gastos de inversión (Ginv) & $1,3 \%$ & $10,1 \%$ & $15,4 \%$ & $6,6 \%$ \\
& Itot-Gtot & $-2,2 \%$ & $2,1 \%$ & $1,8 \%$ & $0,5 \%$ \\
\cline { 2 - 5 } Balance (pp) & Itr-Gf & $-3,7 \%$ & $1,9 \%$ & $0,5 \%$ & $-0,2 \%$ \\
& Itr-Gc & $-4,7 \%$ & $2,0 \%$ & $0,6 \%$ & $-0,5 \%$ \\
& Itot-Gint & $-7,7 \%$ & $4,4 \%$ & $6,0 \%$ & $-0,1 \%$ \\
\hline
\end{tabular}

Fuente: elaboración propia con información del DANE y el Ministerio de Hacienda.

\section{Aspectos metodológicos}

Una vez revisados los aspectos teóricos —además de tener unas referencias generales sobre el desempeño fiscal de Colombia durante el periodo de estudio - se pasa a evaluar la posición cíclica de la política fiscal. Para alcanzar dicho objetivo, inicialmente conviene hacer algunas aclaraciones de tipo metodológico. Más allá del debate sobre cuál debería ser la posición de la política fiscal frente al ciclo económico, otro tema muy importante es cómo determinarla. En varios estudios se ha abordado este tema, y en cada caso las definiciones son muy variadas (Kaminsky et al., 2004; Martner, 2007; Lozano et al., 2013; Klemm, 2014). En principio, hay una discusión sobre 
el nivel de gobierno que se debe analizar: si es el Gobierno Central, el nivel descentralizado o territorial, o el sector público en general. También se discute si el análisis se debe hacer desde la perspectiva del gasto o de los ingresos - $\mathrm{O}$ los dos-, el balance fiscal e incluso con las tasas impositivas.

Desde la óptica del gasto, se propone el uso de diferentes variables, tales como gasto total, gasto corriente, gasto primario, gasto en infraestructura, etcétera (Gavin \& Perotti, 1997; Kaminsky et al., 2004; Talvi y Végh, 2005; Clements et al., 2007; Ilzetzki \& Végh, 2008; Ocampo, 2011; Lozano et al., 2013). En algunas propuestas también se llega a utilizar el gasto de consumo — tomado de las cuentas nacionales- (Kaminsky et al., 2004; Lozano et al., 2013). En otros planteamientos, la variable de referencia es el saldo de la deuda pública (Martner, 2007). Y, por último, otros estudios plantean la utilización del balance fiscal, con diversas definiciones: balance primario, balance total, entre otros, cuyo análisis se extiende a partir de la separación del componente estructural y cíclico de dicho indicador (Martner, 2007; Toro \& Lozano, 2007; Lozano, 2009; Klemm, 2014). En el plano cuantitativo, también se proponen varios métodos para la estimación de los indicadores que al final se usan para la definición de la posición cíclica de la política fiscal.

Dentro de esta investigación, con base en las propuestas de Kaminsky et al. (2004) e Ilzetzki y Végh (2008), la posición de la política fiscal se determinó — fundamentalmente - a partir de la dinámica del gasto. Siguiendo estos planteamientos, es posible medir la posición de la política en mención evaluando las medidas discrecionales, y no los resultados, como puede suceder en el caso del balance fiscal. A pesar de esta aclaración, también se hace el cálculo utilizando dos variables adicionales: el balance fiscal ajustado por el ciclo económico y la deuda pública. En cuanto a los gastos, se adoptan varios indicadores: gasto total, gasto corriente, gasto primario y, en algunos casos, la demanda del gobierno (agregada).

Con relación al nivel de gobierno, se tomaron —básicamente- las cifras del GNC, y solamente en algunas ocasiones se evalúa la posición del SPNF. Esta decisión se explica por varias razones: en primer lugar, este es el nivel de gobierno que se considera con mayor nivel de discrecionalidad, medido tanto por su capacidad de recaudar ingresos como por el nivel de gastos (Lozano, 
Portillo Riascos: La posición cíclica de la política fiscal en Colombia durante el periodo...

2009); en segundo lugar, la disponibilidad de información es mucho más desagregada que en el caso del SPNF; en tercer lugar, la mayoría de estudios referenciados hasta el momento utilizan como base la información del GNC (Toro \& Lozano, 2007; Ilzetzki \& Végh, 2008; Lozano, 2009; Ocampo, 2011; CEPAL, 2014), por lo cual habría un criterio de comparación.

\section{Resultados}

Siguiendo a Kaminsky et al. (2004), la posición de la política fiscal se puede calificar como acíclica, contracíclica o procíclica. Desde la óptica del gasto, la política fiscal será acíclica cuando el componente cíclico del gasto no está relacionado con el ciclo económico. La política fiscal será contracíclica cuando el componente cíclico del gasto es creciente en aquellos periodos en los que la economía se desacelera (o incluso cae en recesión); lo contrario sucedería cuando la economía entra en una fase de auge. Por último, la política fiscal será procíclica cuando el componente cíclico del gasto sigue la dinámica del ciclo económico, es decir, el gasto se expande a igual o mayor ritmo que la tasa de expansión del PIB durante los auges, y se ubica por debajo de dicha tasa durante las crisis.

Con el fin de determinar la relación entre el PIB y el gasto público, se obtuvieron los componentes cíclicos y tendenciales de cada una de las variables, utilizando el filtro Hodrick-Prescott (HP). Posteriormente, se calcularon los coeficientes de correlación parciales. Así, cuando la correlación es positiva, la política fiscal se puede calificar como procíclica; cuando es negativa será contracíclica; y si es cero será acíclica.

De acuerdo con los resultados reportados en la Tabla 4, la política fiscal en Colombia en el periodo 1990-2015 ha tenido un carácter procíclico, y es el GNC el que más se adecúa a dicha calificación. Igualmente, si se toma el gasto de consumo general, obtenido desde las cuentas nacionales, el indicador también resulta estadísticamente significativo. Ahora bien, aunque el gasto total y el gasto primario del GNC muestran una correlación positiva y estadísticamente significativa, no sucede lo mismo cuando se analiza el gasto por cada uno de sus componentes (corrientes, de funcionamiento e intereses de la deuda pública). El único factor que sí tiene una relación con el ciclo 
económico es el gasto de inversión, que al final es el más alto de todos los coeficientes calculados $(0,73)$.

Tabla 4. Correlaciones parciales entre el componente cíclico del PIB real y los indicadores de politica fiscal, periodo 1990-2015

\begin{tabular}{lccc}
\hline Indicador (componente cíclico-filtro HP) & Coeficiente de correlación & Estadístico t & Probabilidad \\
\hline Gasto total (real) GNC & 0,435 & 2,364 & $0,0265^{*}$ \\
Gasto total (real) SPNF & 0,263 & 1,336 & 0,1942 \\
Gasto de consumo (real) gobierno general - & 0,428 & 2,32 & $0,0292^{*}$ \\
cuentas nacionales & 0,478 & 2,663 & $0,0136^{*}$ \\
Gasto primario (real) GNC & 0,263 & 1,336 & 0,1942 \\
Gasto primario (real) SPNF & 0,1625 & 0,8066 & 0,4278 \\
Gastos corrientes (reales) GNC & 0,2999 & 1,5403 & 0,1366 \\
Gastos de funcionamiento (reales) GNC & 0,7305 & 5,2411 & $0,0000^{*}$ \\
Gastos de inversión (reales) GNC & $-0,2941$ & $-1,5075$ & 0,1447 \\
Intereses de la deuda pública (reales) GNC & & &
\end{tabular}

Nota: ${ }^{*}$ significativo al $5 \%$.

Fuente: elaboración propia con información del DANE y el Ministerio de Hacienda.

De acuerdo con los resultados descritos, resulta claro que el ajuste del gasto en los momentos de crisis se hace en el componente más flexible, que es - precisamente- el de la inversión. Por el contrario, los gastos de funcionamiento resultan mucho menos sensibles al ciclo económico, lo cual se explica por dos razones: en primer lugar, por las disposiciones legales, como sucede con las transferencias hacia los gobiernos territoriales; en segundo lugar, por la imposibilidad de ajustar algunos de los rubros, como la deuda pública o las pensiones. Además, dado que algunos gastos se vuelven recurrentes con el tiempo, lo que se ha hecho en Colombia es buscar aumentar los ingresos antes que reducir la carga por la vía del gasto (Junguito \& Rincón, 2004).

A pesar de que los datos mostrados en la Tabla 4 dejan ver la posición de la política fiscal frente al ciclo económico en el periodo conjunto, hasta el momento no se ha podido observar su carácter asimétrico, lo cual implica 
Portillo Riascos: La posición cíclica de la política fiscal en Colombia durante el periodo...

una dinámica distinta entre las épocas de auge de la economía y las de desaceleración o crisis (Gavin \& Perotti, 1997). Siguiendo a Kaminsky et al. (2004), la tasa de crecimiento del PIB se puede dividir entre tiempos buenos y tiempos malos, lo cual permitiría comparar su dinámica frente al gasto. Según este planteamiento, los tiempos buenos corresponden a aquellos años donde la tasa de expansión del PIB se ubica por encima de la mediana del periodo; lo contrario ocurre durante los tiempos malos.

Para determinar la posición de la política fiscal, se toma el cociente entre la tasa de expansión del gasto (en sus distintas definiciones) y la del PIB. Si en los buenos tiempos el cociente es mayor que uno, es un indicador de política fiscal procíclica; si es menor que uno, la posición de la política fiscal sería contracíclica. En los tiempos malos, si el cociente es superior a uno, es un indicador de política fiscal contracíclica; en contraste, si el indicador es menor que uno, estaría indicando un resultado procíclico.

De acuerdo con los resultados reportados en Tabla 5, si bien es cierto que se ratifica el hecho de que la política fiscal ha sido mayormente procíclica, en los tiempos malos la política fiscal termina siendo contracíclica. Ahora bien, dicho resultado también podría interpretarse como un síntoma de la poca flexibilidad del gasto, el cual —en términos generales — tiende a crecer a las mismas tasas independientemente de la fase del ciclo económico. Así, por ejemplo, mientras el gasto total del GNC creció a una tasa anual media del $7,65 \%$ en los periodos expansivos de la economía, en las fases recesivas dicho porcentaje alcanzó el 6,65\%. Lo mismo sucedió con el gasto de consumo general.

Descomponiendo el gasto del GNC, buena parte la diferencia en la tasa de crecimiento de esta variable entre subperiodos está en el gasto primario, lo que es signo del carácter asimétrico de los flujos de intereses de la deuda pública. Así, entonces, mientras los intereses crecieron a una tasa del 3,9\% en los periodos expansivos de la economía, en las fases recesivas lo hicieron al $12,1 \%$. Este fenómeno se explicaría por dos razones: a) en las épocas de crisis el gobierno tiende a endeudarse para cubrir los gastos, algo que es normal, además de que actúa como un instrumento contracíclico; b) el efecto que genera la depreciación de la moneda, asociada a los periodos de 
desaceleración de la economía. Además, habría que contar con que el costo del endeudamiento es mayor en las épocas de crisis.

Tabla 5. Posición cíclica de la politica fiscal en los tiempos buenos y en los tiempos malos

\begin{tabular}{|c|c|c|c|c|c|c|c|c|c|}
\hline \multirow{2}{*}{$\begin{array}{l}\text { Indicador fiscal (tasa } \\
\text { de crecimiento real) }\end{array}$} & \multirow{2}{*}{$\begin{array}{l}\text { Tiempos } \\
\text { buenos }\end{array}$} & \multirow{2}{*}{$\begin{array}{l}\text { Tiempos } \\
\text { malos }\end{array}$} & \multicolumn{2}{|c|}{ Indicador fiscal/PIB } & \multirow{2}{*}{$\begin{array}{c}\text { Promedio } \\
\text { total }\end{array}$} & \multicolumn{4}{|c|}{ Reacción frente a la crisis } \\
\hline & & & $\begin{array}{l}\text { Tiempos } \\
\text { buenos }\end{array}$ & $\begin{array}{c}\text { Tiempos } \\
\text { malos }\end{array}$ & & 1999 & 2000 & 2009 & 2010 \\
\hline PIB & $5,39 \%$ & $2,06 \%$ & 1,00 & 1,00 & $3,7 \%$ & $-4,2 \%$ & $4,4 \%$ & $1,7 \%$ & $4,0 \%$ \\
\hline Gasto total GNC & $7,65 \%$ & $6,65 \%$ & 1,42 & 3,23 & $7,2 \%$ & $6,4 \%$ & $1,7 \%$ & $10,7 \%$ & $-5,9 \%$ \\
\hline Gasto primario GNC & $9,69 \%$ & $5,08 \%$ & 1,80 & 2,46 & $7,4 \%$ & $5,8 \%$ & $-1,7 \%$ & $12,6 \%$ & $-5,8 \%$ \\
\hline $\begin{array}{l}\text { Demanda del gobierno } \\
(\mathrm{CN})\end{array}$ & $6,83 \%$ & $6,97 \%$ & 1,27 & 3,38 & $6,9 \%$ & $3,6 \%$ & $-0,3 \%$ & $6,0 \%$ & $5,6 \%$ \\
\hline Gasto total SPNF & $6,77 \%$ & $5,37 \%$ & 1,26 & 2,60 & $6,1 \%$ & $6,3 \%$ & $2,2 \%$ & $12,8 \%$ & $3,8 \%$ \\
\hline Gasto primario SPNF & $7,27 \%$ & $5,50 \%$ & 1,35 & 2,67 & $6,4 \%$ & $10,7 \%$ & $-0,3 \%$ & $14,4 \%$ & $4,9 \%$ \\
\hline $\begin{array}{l}\text { Gastos corrientes } \\
\text { (reales) GNC }\end{array}$ & $5,9 \%$ & $7,6 \%$ & 1,09 & 3,68 & $6,7 \%$ & $8,4 \%$ & $1,4 \%$ & $11,5 \%$ & $-6,1 \%$ \\
\hline $\begin{array}{l}\text { Gastos de } \\
\text { funcionamiento } \\
\text { (reales) GNC }\end{array}$ & $7,9 \%$ & $7,1 \%$ & 1,46 & 3,45 & $7,5 \%$ & $8,2 \%$ & $-2,6 \%$ & $13,9 \%$ & $-6,1 \%$ \\
\hline $\begin{array}{l}\text { Gastos de inversión } \\
\text { (reales) GNC }\end{array}$ & $15,0 \%$ & $0,6 \%$ & 2,79 & 0,28 & $7,8 \%$ & $-12,2 \%$ & $6,0 \%$ & $5,1 \%$ & $-3,7 \%$ \\
\hline $\begin{array}{l}\text { Intereses de la deuda } \\
\text { pública (reales) GNC }\end{array}$ & $3,9 \%$ & $12,1 \%$ & 0,72 & 5,87 & $8,0 \%$ & $9,1 \%$ & $17,7 \%$ & $1,3 \%$ & $-6,2 \%$ \\
\hline
\end{tabular}

Fuente: elaboración propia con información del DANE y el Ministerio de Hacienda.

Un componente que no se resalta en la mayoría de los estudios, y que en este artículo mostró una posición procíclica tanto en los tiempos buenos como en los malos, es la inversión pública. Así, mientras en los tiempos buenos esta variable creció a un promedio del $15 \%$ por año, en los tiempos malos lo hizo al $6 \%$. Nuevamente, el factor de ajuste se hace por esta vía, y no tanto por el lado de los gastos corrientes. En términos macroeconómicos, se puede decir que la rigidez del gasto contribuye a suavizar el consumo, pero induce a una mayor volatilidad de la inversión.

Para determinar la posición de la política fiscal frente al ciclo económico, además de las medidas citadas hasta el momento, también se han planteado algunos instrumentos que incorporan tanto el saldo de la deuda pública como el balance fiscal ajustado por el ciclo económico. Para Martner (2007), no se 
Portillo Riascos: La posición cíclica de la política fiscal en Colombia durante el periodo...

puede determinar la posición cíclica de la política fiscal si se utiliza como variable de referencia únicamente al gasto.

Incorporando las variables mencionadas, la política fiscal será contracíclica cuando, en los periodos expansivos, la deuda pública reduzca su participación en el PIB o haya una mejora del balance fiscal cíclicamente ajustado. En contraste, en los periodos recesivos aumentaría el saldo de la deuda pública y habría un deterioro del balance del gobierno. Lo contrario sucedería cuando la política fiscal es procíclica.

Desde un punto de vista metodológico, si —en vez de utilizar la brecha del PIB como variable de comparación — se utiliza el gasto público, es posible diferenciar el carácter de la política fiscal dependiendo del momento del ciclo económico (Martner, 2007; CEPAL, 2014). Para este propósito, la brecha del PIB sirve para determinar tanto los periodos expansivos como los recesivos. En este caso, se encontraron tres periodos recesivos (1990-1992, 1999-2005 y 2009-2010) y tres expansivos (1993-1998, 2006-2008 y 2011-2015). El panel A de la Figura 6 representa los periodos expansivos, en tanto el panel B muestra los periodos recesivos. Las variables utilizadas, expresadas en precios constantes, corresponden a los impulsos tanto de la deuda pública como del gasto primario (ambos como porcentajes del PIB).

La principal conclusión de este ejercicio es que -efectivamente- la política fiscal en Colombia fue asimétrica, es decir, en los periodos expansivos (panel A) tendió a ser procíclica, y en los periodos recesivos fue contracíclica. En los dos casos hay excepciones, que corresponden a los periodos 20062008, cuando la política fiscal fue contracíclica (en sentido débil), y 2009-2010, cuando la política fiscal termina siendo procíclica (en sentido débil).

Ahora bien, si la idea es comparar los impulsos de la deuda pública o del balance fiscal (primario y estructural ${ }^{4}$ ) con la brecha del PIB, no habría

4 Para los dos casos, se utilizó el balance cíclicamente ajustado. Siguiendo a Martner (2007, p. 38), el balance cíclicamente ajustado $\left(B_{t}^{C A}\right)$ se define de la siguiente manera: $B_{t}^{C A}=$ $B_{t}-B_{t}^{C}$. Donde $B_{t}$ es el balance fiscal del gobierno y $B_{t}^{C}$ es su componente cíclico. Para realizar el cálculo se tomó la siguiente ecuación: $\frac{I T^{*}}{I T}=\left(\frac{Y *}{Y}\right) \wedge \alpha$, donde $Y$ es el nivel del PIB, $Y *$ es el nivel del PIB de tendencia, IT es el nivel de ingresos tributarios, IT* es el componente estructural de los ingresos tributarios y $\alpha$ es la elasticidad de los ingresos 
Figura 6. Cuadrantes de la politica fiscal (deuda pública y gasto primario), periodo 1990-2015

Panel A. Periodos expansivos ( $p p$ del PIB)

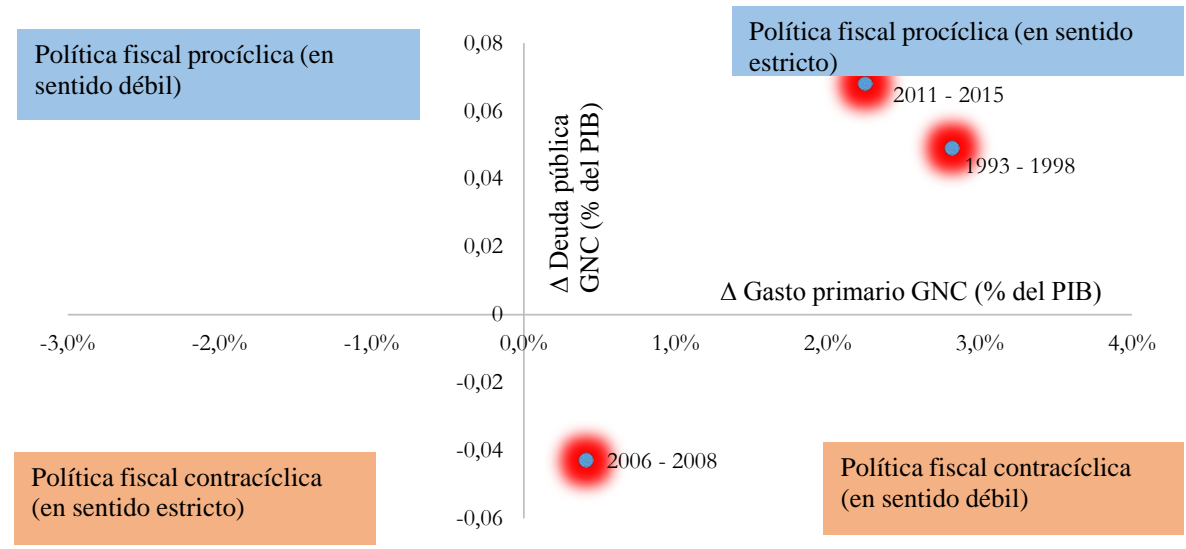

Panel B. Periodos recesivos ( $p$ p del PIB)

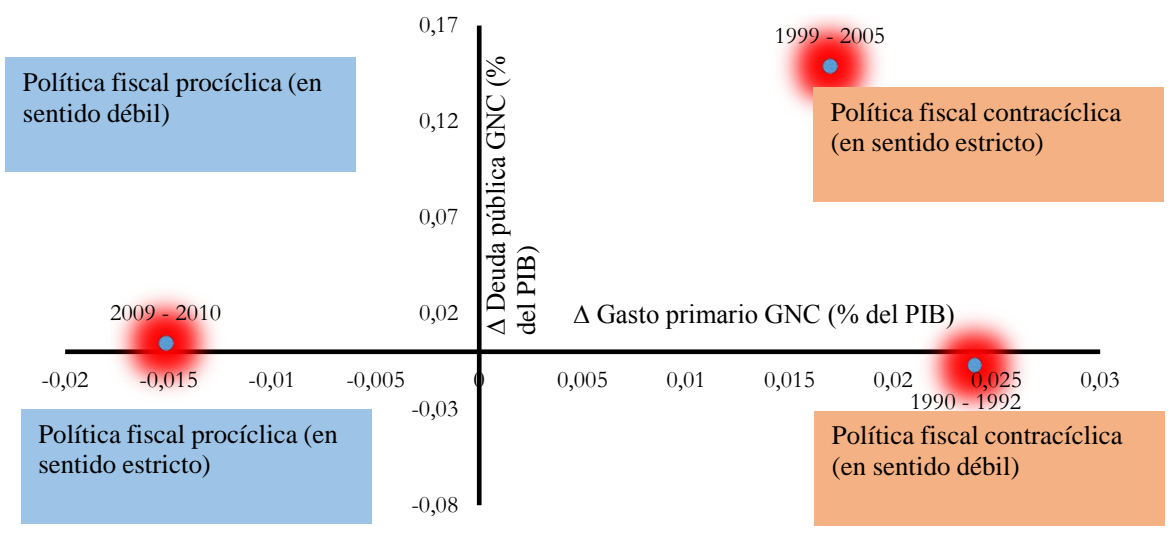

Nota: el desarrollo conceptual y la metodología utilizada se encuentran en Martner (2007).

Fuente: elaboración propia con información del DANE y el Ministerio de Hacienda.

tributarios respecto al PIB. $B_{t}^{C}$ se determinó así: $B_{t}^{C}=T\left(\frac{Y *}{Y}\right) \wedge \alpha$. En el caso de Colombia, la elasticidad producto de los ingresos tributarios se estimó utilizando un MVEC. El número de retardos óptimos es de tres. La elasticidad estimada para el periodo de análisis es de 1,29. 
Portillo Riascos: La posición cíclica de la política fiscal en Colombia durante el periodo...

necesidad de diferenciar entre los periodos recesivos y los expansivos, puesto que estos se incorporan directamente. Siguiendo el planteamiento de Martner (2007), se determinaron los cuadrantes de la política fiscal a partir de las tres variables señaladas (Figura 7). El resultado encontrado es un tanto diferente al que se pudo obtener diferenciando los periodos recesivos de los expansivos, o por lo menos no ofrece la misma claridad que la Figura 6.

A partir de los impulsos de la deuda pública, se encontraron 10 eventos procíclicos y 15 contracíclicos (Figura 7, panel A). Utilizando los impulsos del balance primario cíclicamente ajustado, el resultado fue de 16 eventos procíclicos y 9 contracíclicos (Figura 7, panel B). Asimismo, con el balance total cíclicamente ajustado, el número de eventos procíclicos fue de 17 , frente a 8 eventos contracíclicos (Figura 7, panel C). El resultado global indica 43 eventos procíclicos y 32 contracíclicos (Tabla 6).

Con los nuevos datos aportados, se reafirma el hecho de que la posición de la política fiscal durante el periodo de estudio fue asimétrica y —en mayor medida - procíclica (Tabla 6), especialmente si se toma como referencia el balance primario y el total cíclicamente ajustados. Sin embargo, no se puede extraer el mismo dictamen si se utiliza como variable la deuda pública, la cual indicaría una posición mayormente contracíclica, sobre todo durante los periodos expansivos. En términos metodológicos, resulta mucho más claro el uso de una variable discrecional (como el gasto), y no una de resultado (como el balance fiscal o la deuda pública) (Kaminsky et al., 2004). En el caso de la deuda del GNC —y particularmente la externa-, el saldo total desde mediados de los años 2000 se vio afectado por la dinámica del PIB y la apreciación cambiaria (Lozano, 2009), lo cual plantea dudas respecto a si es realmente una medida discrecional del gobierno.

En el estudio de Martner (2007), la elasticidad estimada para Colombia es de 1,23, aunque el periodo de referencia va desde 1991 hasta el 2005. Para determinar el balance primario cíclicamente ajustado se siguió el mismo procedimiento aplicado al déficit. 
Figura 7. Cuadrantes de la politica fiscal GNC (deuda pública, balance fiscal y brecha del PIB), periodo 1990-2015

Panel A. Impulso de la deuda pública ( $p$ p) y la brecha del PIB

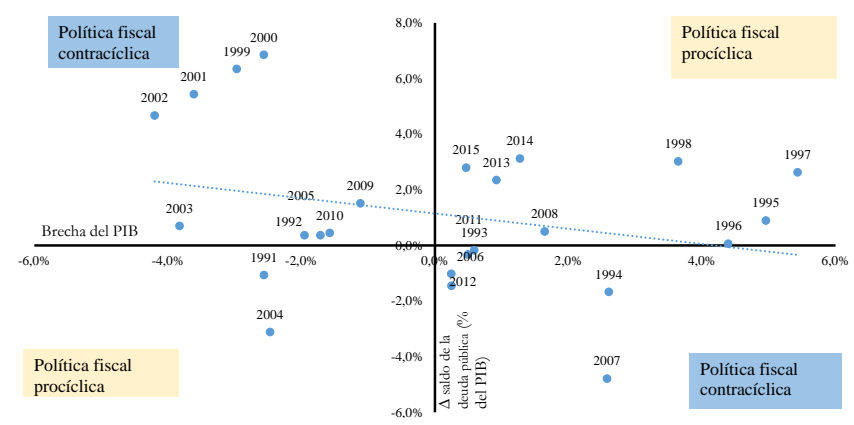

Panel B. Impulso del balance primario ajustado cíclicamente ( $p$ p) y la brecha del PIB

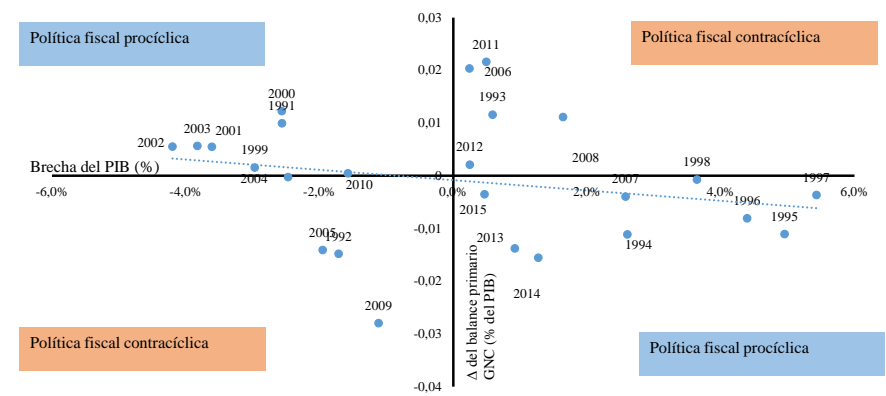

Panel C. Impulso del balance fiscal estructural ( $p$ p) y la brecha del PIB

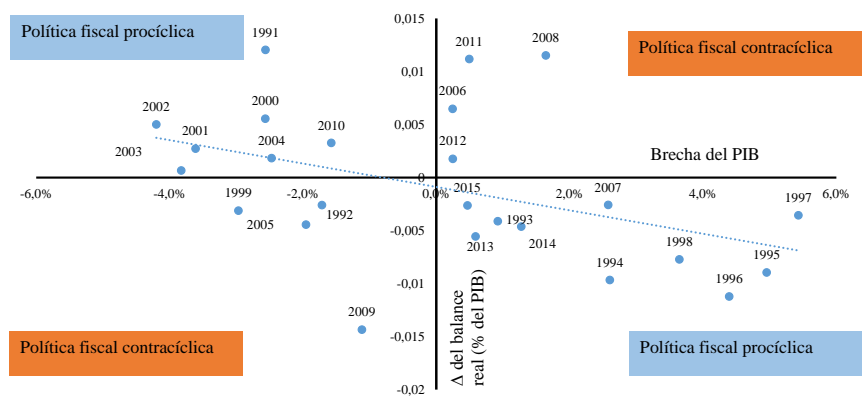

Fuente: elaboración propia con información del DANE y el Ministerio de Hacienda. 
Portillo Riascos: La posición cíclica de la política fiscal en Colombia durante el periodo...

Tabla 6. La posición cíclica de la politica fiscal en los tiempos expansivos y en los tiempos

\begin{tabular}{lcccccc}
\hline Indicador & \multicolumn{3}{c}{ Procíclico } & \multicolumn{3}{c}{ Contracíclico } \\
\cline { 2 - 7 } & $\begin{array}{c}\text { Tiempos } \\
\text { expansivos }\end{array}$ & $\begin{array}{c}\text { Tiempos } \\
\text { recesivos }\end{array}$ & Total & $\begin{array}{c}\text { Tiempos } \\
\text { expansivos }\end{array}$ & $\begin{array}{c}\text { Tiempos } \\
\text { recesivos }\end{array}$ & Total \\
\hline $\begin{array}{l}\text { Impulso del balance primario ajustado } \\
\text { cíclicamente (\% del PIB) }\end{array}$ & 9 & 7 & 16 & 5 & 4 & 9 \\
$\begin{array}{l}\text { Impulso del balance total ajustado cíclica- } \\
\text { mente (\% del PIB) }\end{array}$ & 10 & 7 & 17 & 4 & 4 & 8 \\
Impulso de la deuda pública (\% del PIB) & 8 & 2 & 10 & 6 & 9 & 15 \\
Total & 27 & 16 & 43 & 15 & 17 & 32 \\
\hline
\end{tabular}

Fuente: elaboración propia con información del DANE y el Ministerio de Hacienda.

\section{Un breve análisis formal de la posición de la politica fiscal en Colombia}

En este punto se presenta un análisis formal utilizando un modelo econométrico que muestra la relación entre el componente cíclico del gasto (primario y total) del GNC y el ciclo económico colombiano. Frente a este aspecto, vale advertir que en la literatura se encuentran un sinnúmero de propuestas con distintos tipos de indicadores e instrumentos cuantitativos (Klemm, 2014). En este caso, se optó por un modelo planteado por Ilzetzki y Végh (2008), investigadores que definen la posición cíclica de la política fiscal en la siguiente ecuación:

$$
g_{t}=\beta P I B_{t}+\varepsilon_{t}
$$

Donde $g_{t}$ y $P I B_{t}$ son los componentes cíclicos; es decir, el gasto primario y total del GNC (o el gasto total) y el PIB expresados en términos constantes, y donde $\varepsilon_{t}$ representa un proceso de ruido blanco. De esta manera, la ecuación 1 representa la función de reacción fiscal del GNC, que muestra cómo responde el gasto público ante los movimientos del output. El parámetro $\beta$ mide la posición cíclica de la política fiscal. Si $\beta<0$, la política fiscal es contracíclica; si $\beta=0$, la política fiscal es acíclica; si $\beta>0$, la política fiscal es procíclica. El método utilizado para este ejercicio fue el de mínimos cuadrados ordinarios (MCO) y los resultados obtenidos se muestran en la Tabla 7. Según los resultados para el gasto primario y el gasto total del GNC, se puede afirmar que la política fiscal en Colombia durante el periodo analizado tuvo una posición procíclica, lo cual reafirma los ejercicios que se desarrollaron utilizando otros métodos. 
Tabla 7. La función de reacción fiscal del GNC. Periodo 1990-2015

\begin{tabular}{lcc}
\hline \multicolumn{1}{c}{ Variable independiente } \\
Componente cíclico PIB real & $\begin{array}{c}\text { Variable dependiente } \\
\text { Componente cíclico del gasto } \\
\text { primario del GNC }\end{array}$ & $\begin{array}{c}\text { Comte cíclico del gasto total } \\
\text { del GNC }\end{array}$ \\
\hline Parámetro de la variable & 0,129 & 0,116 \\
Estadístico t & 2,660 & 2,360 \\
Significancia individual (probabilidad) & $0,0136^{*}$ & $0,0265^{*}$ \\
Estadístico F & 7,090 & 5,580 \\
Significancia conjunta (probabilidad) & 0,013 & 0,023 \\
$\mathrm{R}^{2}$ & 0,220 & 0,190 \\
DW & 1,850 & 1,600 \\
\hline
\end{tabular}

Nota: *significativo al $5 \%$.

Fuente: elaboración propia con información del DANE y el Ministerio de Hacienda

\section{Discusión}

Las conclusiones a las que se llegaron dentro de esta investigación con respecto a la posición de la política fiscal frente al ciclo económico son consecuentes, en términos generales, con los hallazgos de otros estudios para Colombia, como los de Toro y Lozano (2007), Lozano (2009) y Ocampo (2011). No obstante, los periodos que se toman son diferentes. En los dos primeros estudios, aunque toman series mucho más largas — 45 años en Toro y Lozano (2007)—, el análisis solamente llega hasta los primeros años de bonanza que se dio durante la segunda mitad de la década del 2000. Además, su variable de referencia es el balance fiscal, que es un resultado y no puede ser tomado como una acción discrecional del gobierno (Kaminsky et al., 2004). A pesar de esta diferencia, lo más importante por resaltar es la persistencia de la asimetría de la política fiscal, que en este caso se pudo mostrar para los años en los que se dio la crisis financiera y económica de los países desarrollados — hacia el 2009_, algo que no se había evaluado en estudios anteriores.

Con respecto al contexto latinoamericano, donde se han realizado varios estudios sobre la posición de la política fiscal frente al ciclo económico, los resultados son consecuentes con los encontrados dentro del presente artículo. En general, se concluye que la política fiscal ha tenido un sesgo procíclico (Gavin \& Perotti, 1997; Clements et al., 2007; Lozano et al., 2013; Klemm, 
2014; CEPAL, 2014). No obstante, se señala que el sesgo procíclico se ha reducido a partir de la década del 2000, y Colombia es uno de los países donde se viene dando dicho fenómeno (Martner, 2007; Klemm, 2014). En este artículo, lo que se argumenta es que esta situación solamente fue posible por el tipo de condiciones fiscales y financieras en que se encontraban los países en el momento en que llegó la crisis de 2007-2009 (Ocampo, 2015), que fueron totalmente diferentes a las de finales de los años noventa.

\section{Conclusiones}

Con base en los hallazgos encontrados, la principal conclusión que se obtuvo es que la política fiscal en Colombia a lo largo del periodo analizado tuvo un comportamiento mayormente procíclico, lo que quiere decir que esta herramienta de política económica actuó como un mecanismo desestabilizador de la demanda agregada y contribuyó a amplificar los efectos generados por los ciclos externos. Ahora bien, el sesgo procíclico no fue uniforme a lo largo del periodo de investigación examinado; en la década de los noventa se encontraron los mayores rasgos de este tipo, lo cual se pudo evidenciar en un crecimiento desmesurado del gasto. Posteriormente, el sesgo procíclico de la política fiscal se redujo; no obstante, esto sucedió en medio de unas condiciones fiscales y financieras excepcionales.

Otro aspecto por resaltar es que la política fiscal fue asimétrica, con lo cual el carácter procíclico se observó fundamentalmente en los periodos de auge de la economía, mostrando diferencias importantes durante las fases de crisis. A la hora de entender dicho fenómeno, se encontró que una parte muy significativa del gasto terminó siendo muy rígida, especialmente aquella que corresponde al componente corriente. Esta situación se explica por dos razones: a) por las obligaciones contraídas por el Estado a partir de la Constitución de 1991, y b) por cuanto, en el transcurso de los años, algunos de los gastos que empezaron siendo coyunturales al final se volvieron recurrentes, lo que deriva en que se tenga que asumir una serie de obligaciones sin considerar el momento del ciclo económico.

Volviendo al plano teórico, lo que se desprende del análisis realizado para el caso colombiano es que la política fiscal fue contracíclica durante algunos 
periodos — fundamentalmente recesivos — no porque fuera una decisión del gobierno, sino porque el gasto resultó muy rígido. Además, en los últimos años la postura contracíclica fue posible gracias a unas condiciones fiscales explicadas por un contexto externo e interno totalmente favorable.

En el plano de la medición, un fenómeno importante que se encontró es que el gasto público no mostró la misma posición frente al ciclo económico en cada uno de sus componentes. Así, aunque los gastos corrientes, que corresponden a la partida más importante del gasto del GNC, tuvieron un sesgo fundamentalmente procíclico, pero asimétrico, no sucedió lo mismo con la inversión (formación bruta de capital fijo [FBKF] pública). En este último caso, tanto en los periodos recesivos como en los expansivos la posición de la política fiscal fue procíclica. Fruto de este hallazgo, se puede afirmar que tanto el consumo como la inversión pública contribuyeron a aumentar el grado de inestabilidad de la demanda agregada; no obstante, fue la FBKF la que más aportó a este fenómeno.

La FBKF se convirtió en el principal ítem de ajuste dentro de la estructura de presupuesto del GNC. En el periodo analizado, el fenómeno descrito obedeció a dos razones: la primera tiene que ver con que la FBKF es la partida más flexible dentro del gasto total, y la segunda se deriva del financiamiento, dada su dependencia de los ingresos extraordinarios. Para la economía en su conjunto, la dinámica que adoptó la FBKF es un aspecto negativo, en la medida en que los cambios de esta variable quedaron supeditados a los ciclos externos, lo cual es un síntoma claro de VM. Además, se entiende que, debido a las continuas fluctuaciones de la inversión pública, estas pierden eficiencia y reducen su aporte en términos del PIB.

Más allá del análisis del gasto público, el sesgo procíclico de la política fiscal también se pudo observar a partir del examen del déficit público (primario y total). Y aunque esta variable mostró un cambio muy importante desde finales de los noventa, al final dicho déficit ha persistido, incluso en aquellas fases en las que el GNC se benefició por un incremento notable tanto de los ingresos corrientes como de los de capital. 
Portillo Riascos: La posición cíclica de la política fiscal en Colombia durante el periodo...

\section{Referencias}

Agénor, P. \& Montiel, P. (2000). La macroeconomía del desarrollo (primera edición). Fondo de Cultura Económica.

Atkins, J., Mazzi, S. \& Ramlogan, C. (1998). A study of the vulnerability of developing and island states: a composite index. Commonwealth Secretariat.

Briguglio, L., Cordina, G., Farrugia, N. \& Vella, S. (2009). Economic Vulnerability and Resilience: Concepts and Measurements. Oxford Development Studies, 37(3), 229-247. https://doi.org/10.1080/136008 10903089893

Campodónico, H. (2004). Reformas e inversión en la industria de hidrocarburos de América Latina. CEPAL.

Comisión Económica para América Latina y el Caribe [CEPAL] (2001). Crecer con estabilidad: el financiamiento del desarrollo en el nuevo contexto internacional. CEPAL.

Comisión Económica para América Latina y el Caribe [CEPAL] (2014). Cambio estructural para la igualdad: una visión integrada del desarrollo. CEPAL.

Cordina, G. (2004). Economic vulnerability and economic growth: some results from a Neo-Classical Growth Modelling Approach. Journal of Economic Development, 29(2), 21-39. https://citeseerx.ist.psu.edu/view doc/download?doi=10.1.1.631.1809\&rep=rep1\&type=pdf

Clements, B., Faircloth, C. \& Verhoeven, M. (2007). Gasto público en América Latina: tendencias. Revista de la CEPAL, 93, 39-62. https://ww w.cepal.org/sites/default/files/publication/files/37448/RVE93_es.pdf

Echeverry, J.C., Bonilla, A., \& Moya, A. (2006). Rigideces institucionales y flexibilidad presupuestaria: los casos de Argentina, Colombia, México y Perú [Documentos CEDE, 33]. Universidad de los Andes. http: //hdl.handle.net/1992/8013 
Eichengreen, B., Hausmann, R. \& Panizza, U. (2007). Currency Mismatches, Debt Intolerance, and the Original Sin: Why They Are Not the Same and Why It Matters. En Edwards, S. (ed.), Capital controls and capital flows in emerging economies: Policies, practices and consequences (pp. 12164). Universidad de Chicago.

Ffrench-Davis, R. (2008). From financieristic to real macroeconomics: Seeking development convergence in emerging economies. Banco Mundial.

Ffrench-Davis, R. (2010). Macroeconomía para el desarrollo: desde el financierismo al productivismo. Revista de la CEPAL, 102, 7-27. https: //www.cepal.org/es/publicaciones/37386-revista-cepal-no102

Ffrench-Davis, R. (Ed.). (2005). Crecimiento esquivo y volatilidad financiera. CEPAL.

Ffrench-Davis, R. y Ocampo, J. A. (2001). Globalización de la volatilidad financiera: desafíos para las economías emergentes. En Ffrench-Davis, R. (comp.), Crisis financieras en paises exitosos (pp. 1-41). CEPAL.

Gavin, M. \& Perotti, R. (1997). Fiscal Policy in Latin America. En Bernanke, B. \& Rotemberg, J. (Eds.), NBER Macroeconomics Annual (pp. 11-61). MIT Press.

Guillaumont, P. (2013). Measuring structural vulnerability to allocate development assistance and adaptation resources [Development Policies Working Paper, 68]. Fondation pour les Etudes et Recherches sur le Développement International (Ferdi). https://ferdi.fr/dl/df-PtBxCEF uP49c6ps2a9YHxvha/ferdi-p68-measuring-structural-vulnerability- $t$ o-allocate-development.pdf

Guillaumont, P. (2017). Vulnerability and Resilience: A Conceptual Framework Applied to Three Asian Countries Bhutan, Maldives and Nepal [ADB South Asia Working Paper Series, 53]. Asian Development Bank. http://dx.doi.org/10.22617/WPS179069-2

Ilzetzki, E. \& Végh, C. (2008). Procyclical fiscal policy in developing countries: Truth or fiction? [NBER Working Paper, 14191]. https: //econpapers.repec.org/paper/nbrnberwo/14191.htm 
Portillo Riascos: La posición cíclica de la política fiscal en Colombia durante el periodo...

Jiménez, J. \& Fanelli, J. (2009). Crisis, volatilidad, ciclo y politica fiscal en América Latina. CEPAL.

Junguito, R. \& Rincón, H. (2004). La política fiscal en el siglo XX en Colombia [Borradores de Economía, 318]. Banco de la República. https://www.banrep.gov.co/sites/default/files/publicaciones/pdfs /borra318.pdf

Kaminsky, G. L., Reinhart, C. M. \& Végh, C. A. (2004). When It Rains, It Pours: Procyclical Capital Flows and Macroeconomic Policies. NBER Macroeconomics Annual 2004, 19. https://www.nber.org/chapters/c6 668.pdf

Klemm, A. (2014). Fiscal policy in Latin America over the Cycle [IMF Working Papers, 14/59]. Fondo Monetario Internacional. https://ww w.imf.org/en/Publications/WP/Issues/2016/12/31/Fiscal-Policy-in-La tin-America-over-the-Cycle-41480

Larraín, B. \& Parro, F. (2008). Chile menos volátil. El Trimestre Económico, 75(299), 563-596. https://doi.org/10.20430/ete.v75i299.412

Loayza, N. V. \& Raddatz, C. (2007). The Structural Determinants of External Vulnerability. The World Bank Economic Review, 21(3), 359-387. https: //doi.org/10.1093/wber/lhm018

Lozano, I. (2009). Caracterización de la política fiscal en Colombia y análisis de su postura frente a la crisis internacional. Borradores de Economía, 566. https://www.banrep.gov.co/sites/default/files/publicaciones/pdfs /borra566.pdf

Lozano, I., Melo, L. \& Ramos, J. (2013). Flujos de capitales y política fiscal en las economías emergentes de América Latina. En Rincón, H. \& Velasco, A. (eds.), Flujos de capitales, choques externos y respuestas de politicas en paises emergentes (1.a ed., pp. 533-564). Banco de la República.

Lozano, I., Rincón, H., Sarmiento, M., \& Ramos, J. (2008). Regla fiscal cuantitativa para consolidar y blindar las finanzas públicas de Colombia. Revista de Economia Institucional, 10(19), 311-352. https://revistas.uex ternado.edu.co/index.php/ecoins/article/view/337 
Martner, R. (2007). La politica fiscal en tiempos de bonanza. CEPAL.

Ocampo, J. A. (2007). La macroeconomía de la bonanza económica latinoamericana. Revista de la CEPAL, 93, 7-29. https://www.cepal. org/es/publicaciones/37448-revista-la-cepal-no93

Ocampo, J. A. (2011). Macroeconomía para el desarrollo: políticas anticíclicas y transformación productiva. Revista de la CEPAL, 104, 13-41. https: //www.cepal.org/es/publicaciones/37373-revista-cepal-no104

Ocampo, J. A. (2012). Balance of Payments Dominance: Its Implications for Macroeconomic Policy. Universidad de Columbia.

Ocampo, J. A., Malagón, J., \& Betancur, J. (2015). La banca central colombiana en una década de expansión, 2003-2013. Universidad Externado de Colombia.

Pérez, E. (2015). Una coyuntura propicia para reflexionar sobre los espacios para el debate y el diálogo entre el (neo) estructuralismo y las corrientes heterodoxas. En Bárcena, A. \& Prado, A. (eds.), Neoestructuralismo y corrientes heterodoxas en América Latina y el Caribe a inicios del siglo XXI (pp. 33-91). CEPAL.

Pineda, R. \& Cárcamo-Díaz, R. (2013). Política monetaria, cambiaria y macroprudencial para el desarrollo volatilidad y crecimiento en América Latina y el Caribe, 1980-2011. CEPAL.

Portillo, L. H. (2015). Los modelos de explotación petrolera de Ecuador y Colombia: un análisis desde el extractivismo y el neoextractivismo (segunda parte). Tendencias, 16(2), 13-35. https://doi.org/10.22267/r tend.151602.19

Portillo, L. H. (2020a). Los orígenes de la vulnerabilidad macroeconómica y sus principales efectos: propuesta de un marco teórico. Iberoamerican Journal of Development Studies 9(2), 208-229. https://doi.org/10.267 54/ojs_ried/ijds.474

Portillo, L. H. (2020b). El concepto de vulnerabilidad macroeconómica. Una revisión de la literatura. Sociedad y economía, 40, 99-118. https://doi.or g/10.25100/sye.v0i40.8020 
Portillo Riascos: La posición cíclica de la política fiscal en Colombia durante el periodo...

Ramey, G. \& Ramey, V. (1995). Cross-country Evidence on the Links between Volatility and Growth. The American Economic Review, 85, 1138-1151. https://www.jstor.org/stable/2950979? origin=JSTO R-pdf\&seq=1

Rentería, C., \& Echeverry, J. C. (2007). Presupuestar en Colombia: buscando la gobernabilidad fiscal a través del presupuesto. Serie Gestión Pública, 61, CEPAL - Naciones Unidas.

Rincón, H., Berthel, J. \& Gómez, M. (2004). Balance fiscal estructural y cíclico del gobierno nacional central de Colombia, 1980-2000. Ensayos sobre Politica Económica, 21(44), 12-62. https://doi.org/10.32468/Esp e. 4401

Talvi, E. \& Vegh, C. A. (2005). Tax base variability and procyclical fiscal policy in developing countries. Journal of Development Economics, 78(1), 156190.

Thirlwall, A. P. (1979). The Balance of Payments Constraint as an Explanation of International Growth Rates Differences. Banca Nazionale del Lavoro Quarterly Review, 128, 45-53. https://ojs.uniroma1.it/index.php/PS LQuarterlyReview/article/viewFile/9407/9302

Titelman, D. \& Pérez, E. (2015). Macroeconomía para el desarrollo en América Latina y el Caribe: nuevas consideraciones sobre las políticas anticíclicas. En Bárcena A. \& Prado, A. (eds.), Neoestructuralismo y corrientes heterodoxas en América Latina y el Caribe a inicios del siglo XXI (pp. 155-184). CEPAL.

Toro, J. \& Lozano, I. (2007). Fiscal Policy Throughout the Business Cycle: The Colombian Experience. Ensayos sobre Politica Económica, 25(55), 12-39. https://doi.org/10.32468/Espe.5501 